\title{
BREEDING PERFORMANCE IN RELATION TO NEST-SITE SUBSTRATUM IN A BUFF-NECKED IBIS (THERISTICUS CAUDATUS) POPULATION IN PATAGONIA ${ }^{1}$
}

\author{
José A. Donázar \\ Estación Biológica de Doñana, CSIC, Avda $M^{a}$ Luisa s.n., 41013 Sevilla, Spain \\ Olga Ceballos \\ Grupo de Estudios Biologicos Ugarra, Carlos III 19, 31002 Pamplona, Spain \\ Alejandro Travaint and Alejandro Rodriguez \\ Estación Biologica de Doñana, CSIC Avda Ma Luisa s.n., 41013 Sevilla, Spain \\ MARTIN Funes \\ Centro de Ecología Aplicada del Neuquén, Casilla de Correos 92, \\ 8371 Junín de los Andes, Neuquén, Argentina \\ Fernando Hiraldo \\ Estación Biologica de Doñana, CSIC Avda $M^{a}$ Luisa s.n., 41013 Sevilla, Spain
}

\begin{abstract}
In northern Argentinean Patagonia, Buff-necked Ibis (Theristicus caudatus) nest on different substrata: cliffs, trees, and marsh vegetation. According to the ideal-free distribution hypothesis, this polymorphism may be due to the occupation of the best breeding habitats by dominant individuals and the relegation of the subdominant birds to marginal substrata with a lower probability of achieving successful breeding. We investigated whether there were any variations in the breeding performance among colonies and whether these variations were related to the breeding substratum. Laying date varied from the third week of September to the last week of October, laying occurring earlier in colonies at lower elevations. Clutch size per colony varied between 1.8 and $2.0(x 1.9, n=106)$, but significant differences were not detected among colonies. Brood size per colony varied significantly, ranging between 1.3 and $2.0(\bar{x}=1.8, n=164)$. The substratum of breeding did not influence variations in any of these three parameters. The physical condition of the chicks did not vary among substrata, but there was inter-colony variation in broods of two chicks. Daily rates of nest losses were similar among colonies reaching $6.2 \%(n=856)$ during incubation and $1.4 \%(n=966)$ during the nestling period. Brood reduction was low; the daily mortality rate of chicks $(0.7 \%, n=934)$ did not vary among colonies. The most common known cause of nest and chick losses was predation. These results indicate that breeding success varied only slightly from one colony to the other and that these variations are independent of the nesting substratum. In consequence, birds would not prefer one substratum over another.
\end{abstract}

Key words: Nest-site polymorphism; habitat saturation; daily mortality; reproductive success; Buff-necked Ibis; Theristicus caudatus; Argentina.

\section{INTRODUCTION}

Nest-site selection is closely related to individual fitness since it influences the probability of successfully raising offspring (Martin 1988). The main selective pressure related to nest loss due to nest-site is predation (Lack 1954, Ricklefs 1969, Nilsson 1984). Factors such as inclement weather and proximity to feeding places may also influence species of small body-size. Larger spe-

\footnotetext{
${ }^{1}$ Received 24 January 1994. Accepted 24 May 1994.
}

cies are better able to tolerate weather oscillations and can make long-distance trips in search of food (Collias and Collias 1984).

Quality differs among nest-sites. Many avian studies have shown intraspecific variations in breeding success in relation to nesting substratum. Nests in places not easily accessible to predators, such as cliffs, tall trees, thick vegetation, have high breeding success (e.g., Ames and Merserau 1964, Simmons and Smith 1985, Burger 1984, Martin and Roper 1988, Dunham 1990, $\mathrm{Li}$ and Martin 1991, Alonso et al. 1991, Watson 1992, Kelly 1993). Nests placed on the ground 
among sparse vegetation face a greater predation risk. Nests placed over deep water or surrounded by it have reduced risk (Burger and Gochfeld 1987).

Since selection pressure for nest-sites is intense, the choice of less safe places should be maladaptive. As a rule, such a choice could occur when competitive pressure for the best sites is very strong (e.g., in saturated populations). The individuals with lesser competitive abilities would then be relegated to suboptimal sites (Brown 1969, Alatalo et al. 1985, Nilsson 1987, Li and Martin 1991, Newton 1991, Dhondt et al. 1992). Only when all the potential nesting substrata have a similar risk of nest loss can one expect polymorphism in site selection (Orians and Wittenberg 1991).

The Buff-necked Ibis (Theristicus caudatus) is a large ibis, 71-81 cm long (Hancock et al. 1992), weighing around $1,300 \mathrm{~g}$ (Donázar et al. unpubl. data). It breeds over much of South America and is common in the southern part of the continent (Argentina, Chile) where it is mainly migratory (Narosky and Yzurieta 1988, Hancock et al. 1992). Buff-necked Ibises have broad nest-site requirements: it is possible to find nests in cliffs, scattered trees, woodlots, and poles. Nests on the ground are usually concealed by aquatic vegetation (Hancock et al. 1992). Nesting seasons, which are not yet well known, range from September to December in southern populations (Hancock et al. 1992, Matheu and Del Hoyo 1992).

In this paper, we describe the breeding performance of a Buff-necked Ibis population in northern Argentinean Patagonia, where nests are placed in cliffs, in woodlots, and on the ground in the middle of marsh vegetation ("mallines"). We examine whether breeding success differs according to the substratum on which the colonies are set. According to the despotic-free distribution hypothesis (see Alatalo et al. 1985), we expect that the polymorphism in the nest-site substrate selection by the Buff-necked Ibis population of our study area is maintained because dominant individuals occupy the best nesting substrates relegating the subdominant birds to less safe places. Therefore, it can be predicted that the substrata where the birds could expect to be more successful at breeding will be occupied sooner, so egg-laying will take place earlier. Additionally, we predict that the birds occupying the best colonies must be individuals of higher quality and will therefore produce an offspring in better physical condition (Ferrer 1992).

\section{STUDY AREA AND METHODS}

This study was carried out in the Neuquén Province, northern Argentinean Patagonia. The study area comprised a circle of $60-70 \mathrm{~km}$ radius centered at the locality of Junín de los Andes (39 $57^{\prime} \mathrm{S}$ and $71^{\circ} 51^{\prime} \mathrm{W}, 780 \mathrm{~m}$ a.s.l.). The area belongs to the Patagonian Phytogeographic Province, Western District (Cabrera 1976). The vegetation is characterized by a mixed steppe of grass and shrubs. Dominant species are Mullinum spinosum, Senecio sp., Stipa sp. and Poa sp., while common shrubs are Chacaya trinervis, Berberis darwinii and Schinus molle. The weather is dry and cold, with frosts almost all the year round and frequent snowfalls in winter. Mean, mean highest and lowest annual temperatures are $11,17.4$ and $2.5^{\circ} \mathrm{C}$, respectively, mean annual rainfall is $350-800 \mathrm{~mm}$.

The area comprises high plains ( $800-900$ a.s.1.), dissected by steep rugged areas and valleys of different sizes. In the bottom of these valleys there are marsh zones with dense herbaceous vegetation, called "mallines," where dominant species are Cortadeira araucana, Juncus sp. and Carex sp. Arboreal species like Maytenus boasia and Salix humboldtiana are frequent in valleys and mallines. Pine plantations (Pinus spp.) are also present in the study area.

The Buff-necked Ibis is abundant in this area, with colonies nesting on cliffs (basaltic or sedimentary rocks), in woodlots (native trees and conifer plantations) and on the ground in marsh zones (mallines), where nests are set at just a few centimeters from the water surface in rush masses and at the base of small willows. The birds forage in humid and dry pasture.

In 1991 and 1992, we examined ten colonies situated at 600 to $950 \mathrm{~m}$ a.s.l. Four of them were placed on rocks, three in trees and three in mallines. Colony size (number of breeding pairs) was very variable, the maximum number of active nests observed during a visit in each colony ranging from 8 to 43 (Table 1). From October to December we made an average of 2.8 visits/colony. The average interval between one visit and the next was 11.2 days $(\mathrm{SD}=5.5$, range $=1-21$, $n=12$ ). Visit frequency and duration (maximum two hours) were minimized so as to prevent excessive disturbance to the birds. As each colony was spread over a relatively large area, we usually 
TABLE 1. Maximum number of active nests observed during the breeding season (asterisks show colonies that were totally monitored), laying date (August $1 \mathrm{st}=1$ ), clutch size and brood size in the ten studied colonies and during the two study years (1991 and 1992). For each parameter the average \pm SD and sample size (in brackets) are given. The substrata on which the nests were placed are shown in brackets $(\mathrm{CL}=\mathrm{Cliff}, \mathrm{TR}=\mathrm{Tree}, \mathrm{MS}=$ Marshes-Mallin).

\begin{tabular}{|c|c|c|c|c|c|}
\hline Colony & Year & $\begin{array}{l}\text { Number } \\
\text { of nests }\end{array}$ & Laying date & Clutch size & Brood size \\
\hline \multirow[t]{3}{*}{$1(\mathrm{CL})$} & 91 & $28^{*}$ & $50 \pm 17(21)$ & $2.0 \pm 1.0(3)$ & $2.1 \pm 0.5(18)$ \\
\hline & 92 & $30^{*}$ & $51 \pm 22(30)$ & - & $1.9 \pm 0.5(23)$ \\
\hline & Total & & $51 \pm 20(51)$ & $2.0 \pm 1.0(3)$ & $2.0 \pm 0.5(41)$ \\
\hline \multirow[t]{3}{*}{$2(\mathrm{CL})$} & 91 & 32 & $61 \pm 18(17)$ & $1.7 \pm 0.5(4)$ & $2.1 \pm 0.5(10)$ \\
\hline & 92 & 43 & $51 \pm 11(28)$ & - & $1.6 \pm 0.7(19)$ \\
\hline & Total & & $55 \pm 15(45)$ & $1.7 \pm 0.5(4)$ & $1.8 \pm 0.7(29)$ \\
\hline $3(\mathrm{CL})$ & 92 & $14^{*}$ & $86 \pm 12(11)$ & $2.0 \quad$ (1) & $2.0 \quad$ (1) \\
\hline $4(\mathrm{CL})$ & 92 & 8 & $76 \pm 24(8)$ & - & $1.5 \pm 0.6(4)$ \\
\hline \multirow[t]{3}{*}{5 (TR) } & 91 & $38^{*}$ & $72 \pm 15(26)$ & $2.0 \pm 0.5(27)$ & $1.8 \pm 0.6(10)$ \\
\hline & 92 & $21^{*}$ & $90 \pm 21(18)$ & $2.2 \pm 0.4(11)$ & $1.8 \pm 0.4(5)$ \\
\hline & Total & & $80 \pm 19(44)$ & $2.1 \pm 0.5(38)$ & $1.8 \pm 0.6(15)$ \\
\hline \multirow[t]{3}{*}{6 (TR) } & 91 & 42 & $71 \pm 17(44)$ & $1.6 \pm 0.6(5)$ & $1.8 \pm 0.4(19)$ \\
\hline & 92 & 40 & $81 \pm 24(25)$ & $1.9 \pm 0.3(27)$ & $1.7 \pm 0.5(10)$ \\
\hline & Total & & $75 \pm 20(69)$ & $1.8 \pm 0.5(32)$ & $1.8 \pm 0.4(29)$ \\
\hline 7 (TR) & 92 & 23 & $71 \pm 20(22)$ & $1.8 \pm 0.4(5)$ & $1.7 \pm 0.5(15)$ \\
\hline \multirow[t]{3}{*}{8 (MS) } & 91 & 30 & $81 \pm 5(30)$ & $2.0 \pm 0.7(14)$ & $1.3 \pm 0.5(15)$ \\
\hline & 92 & 17 & $68 \pm 16(17)$ & $1.8 \pm 0.4(6)$ & $1.7 \pm 0.5(7)$ \\
\hline & Total & & $76 \pm 12(47)$ & $1.9 \pm 0.6(20)$ & $1.4 \pm 0.5(22)$ \\
\hline 9 (MS) & 92 & 13 & $61 \pm 15(13)$ & $2.0 \quad$ (1) & $1.7 \pm 0.6(3)$ \\
\hline 10 (MS) & 92 & 16 & $47 \pm 16(15)$ & $2.0 \pm 0.0(2)$ & $1.6 \pm 0.5(9)$ \\
\hline
\end{tabular}

did not stay in any one spot longer than $20 \mathrm{~min}$, allowing the adults to return when we moved to other colony zones. In colonies placed in trees or in mallines not all the nests were visited to avoid excessive disturbance to birds. Three of the colonies (numbers 2, 3, and 4) located on cliffs were monitored with telescopes $(20-77 \times)$.

Every colony was visited at least once when there were a maximum number of hatchlings. During every visit the number of occupied nests together with their contents (number of eggs and/ or nestlings) were noted. In a certain number of nests per colony hatchling measurements were carried out $(n=112)$. Mass $(\mathrm{g})$, tarsus length $(\mathrm{mm})$ and seventh primary length $(\mathrm{mm})$ were recorded. This feather development helped us to determine the nestling hatching date by comparing the development with feather development of nestlings of known age of other avian species (Springer and Osborne 1983, Bechard et al. 1985, Donázar and Ceballos 1989). The contents of nests not directly visited were classified into one of the following categories: adult sitting in the nest (eggs or hatchlings $<5$ day old; if the nest interior could be seen, the number of eggs or hatchlings was recorded); hatchling in grey down and primaries less than $50 \mathrm{~mm}$ long (5-15 days); hatchling with head in down, contour feathers present (15-25 days); hatchling wholly feathered ( $25-35$ days); fledgling ( $>35$ days). Any corpse in the nest or its surroundings and the apparent cause of death were also recorded.

An average egg-laying date for each colony was estimated so as to establish a laying date range for the colonies as a whole. It was not possible to estimate this parameter exactly since the number of visits was minimized in order to reduce disturbance. To estimate the egg-laying date for every nest, 28 days were added to the hatchling age (if the primary had been measured) or to the average age of the category it belonged to if it had been observed from a distance (see above). Those 28 days correspond to the incubation period (Hancock et al. 1992). If there was an adult sitting in the nest, it was estimated that the bird was in the middle of the period that includes hatching and the first five days in hatchling life. Breeding success (number of grown chicks/successful nest) was estimated only on nests containing chicks that had almost completed their skeletal growth (chicks more than 25 days old).

Chick quality was estimated by comparing predicted mass to actual mass. Predicted mass was calculated by means of a lineal regression 


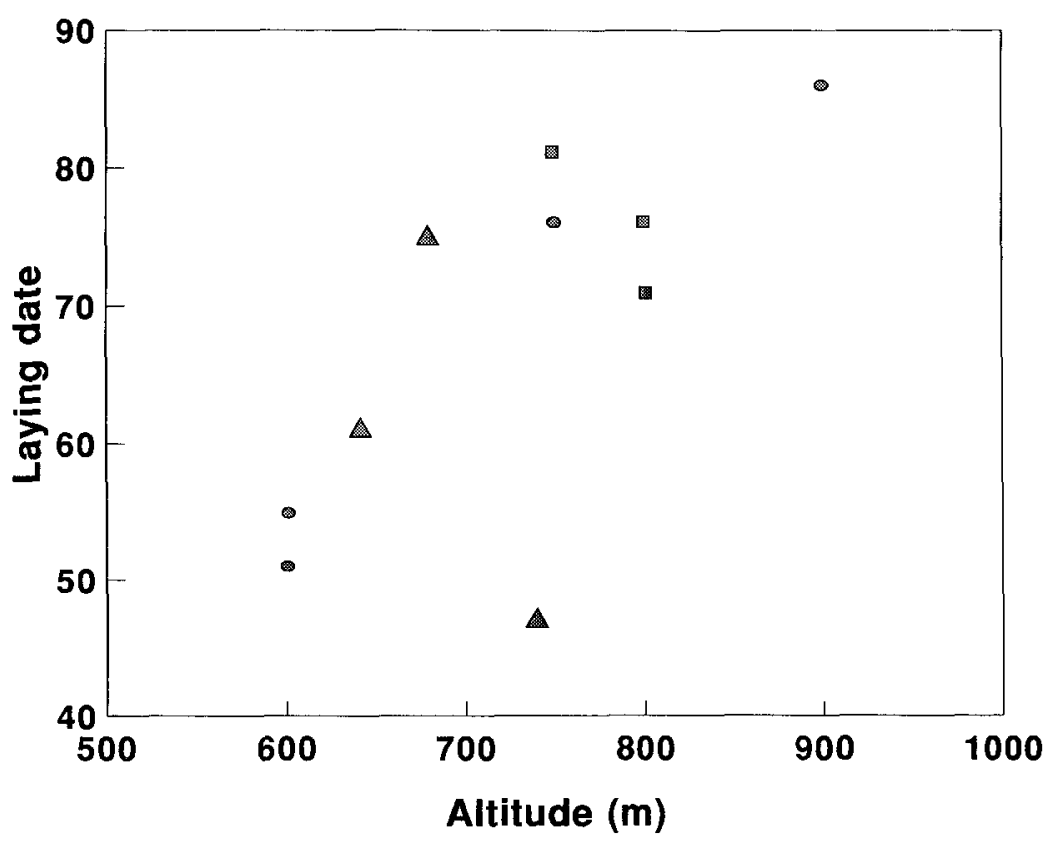

FIGURE 1. Relationship between altitude and mean laying date (August 1st $=1$ ) in six colonies. Symbols signal the substratum where the colonies were placed: Circle $=$ cliff, square $=$ tree, triangle $=$ marsh-malline.

carried out with all the hatchlings, namely, log tarsus length minus log mass. This regression produced the following model: $\log$ mass $=1,683$ log tarsus $-0.232(r=0.966, \mathrm{df}=101, P=$ 0.001 ). The percentage representing the difference between the actual from the forecast weight was taken as an index of the bird's physiological condition, as has been done in other studies (see review in Sparling et al. 1992). Index values around 0 are considered normal.

In eight colonies the contents of several nests were examined more than once. This allowed us to estimate the daily rate of nest loss by means of Mayfield's method; $40 \%$ of modification was applied when the interval between visits was longer than 15 days (see review in Johnson 1979). The differences among colonies were tested by the method proposed by Johnson (1979), a Bonferroni's sequential correction (Rice 1989) being later applied to the results. Survival estimates by census of the young can be underestimated in the case of Ciconiiforms when the nests are in dense vegetation, since many chicks in the mobile stage can have left the nest, unnoted by the observer (Frederick et al. 1993). In colonies of Buff-necked Ibis on cliffs, visibility is total, while in marsh vegetation any chick could hide in the vegetation during the mobile stage. So all nest surroundings were carefully inspected during the visits carried out at that stage.

\section{RESULTS}

\section{EGG-LAYING DATE}

Egg-laying occurred from the third week of September to the last week of October. The mean laying date varied interannually in two of the five colonies examined (Mann-Whitney $U$-tests; colonies 5 and $8<0.01$ ). For further estimates we used the average of the two years in these two colonies. The egg-laying date was independent of the nesting substratum (Table 1) (KruskalWallis $=2.63, P>0.25$ ). Egg-laying date was directly related to colony altitude (Fig. 1), the higher altitudes being associated with later egglaying dates $(r=0.79, n=10, P=0.02)$. Although the small sample size at any altitude precludes analyzing the effect of nesting substratum on egg-laying date examining Figure 1 suggests that the egg-laying date of cliff colonies was not earlier than that of colonies nesting on a different substratum at a similar altitude.

\section{CLUTCH SIZE}

The examined clutches $(n=106)$ had one $(n=$ $18)$, two $(n=76)$, or three eggs $(n=12)$ (mean 
TABLE 2. Nestling physical condition (actual weight - predictable weight $\times 100$ /predictable weight) in eight colonies. The predictable weight was estimated according to tarsus development (see Methods). Different brood sizes (number of chicks older than 25 days/successful nest) are distinguished.

\begin{tabular}{|c|c|c|c|c|c|c|c|}
\hline \multirow[b]{2}{*}{ Colony } & \multirow[b]{2}{*}{ Year } & \multicolumn{3}{|c|}{ Brood size $=1$} & \multicolumn{3}{|c|}{ Brood size $=2$} \\
\hline & & $\bar{x}$ & $\mathrm{SE}$ & $n$ & $\bar{x}$ & $\mathrm{SE}$ & $\bar{n}$ \\
\hline \multirow[t]{3}{*}{$1(\mathrm{CL})$} & 91 & - & - & - & -11.1 & 10.6 & 14 \\
\hline & 92 & - & - & - & -6.6 & 7.8 & 13 \\
\hline & Total & & & & -8.9 & 1.9 & 27 \\
\hline \multirow[t]{3}{*}{4 (TR) } & 91 & - & - & - & -3.6 & 7.3 & 10 \\
\hline & 92 & 2.4 & 10.2 & 2 & -0.6 & 7.8 & 4 \\
\hline & Total & 2.4 & 10.2 & 2 & -2.8 & 1.9 & 14 \\
\hline \multirow[t]{3}{*}{5 (TR) } & 91 & -5.6 & 1.2 & 2 & 5.0 & 7.1 & 14 \\
\hline & 92 & 4.8 & 2.2 & 2 & 4.2 & 6.2 & 8 \\
\hline & Total & -0.4 & 3.1 & 4 & 5.2 & 1.3 & 22 \\
\hline 6 (TR) & 92 & - & - & - & -5.7 & 4.6 & 6 \\
\hline \multirow[t]{3}{*}{8 (MS) } & 91 & 4.5 & 8.2 & 6 & 8.6 & - & 1 \\
\hline & 92 & 8.7 & 2.0 & 2 & -0.2 & 6.2 & 6 \\
\hline & Total & 5.6 & 2.6 & 8 & -1.4 & 2.5 & 7 \\
\hline 9 (MS) & 92 & 12.6 & - & 1 & -0.7 & 3.6 & 6 \\
\hline 10 (MS) & 92 & 2.4 & 3.4 & 5 & 2.6 & 3.1 & 10 \\
\hline
\end{tabular}

$=1.9, n=106)$. In the colonies inspected throughout the two year study, no significant differences in clutch size were detected (MannWhitney $U$-tests) : colony $5, z=0.78, P=0.44$; colony $6, z=0.93, P=0.35$; colony $8, z=-0.49$, $P=0.63$. Clutch size variation among colonies was also very slight: in five colonies. (one on rock, three in trees and one in malline) with five or more clutches inspected, it ranged from 1.8 to 2.0 eggs/nest (Kruskal-Wallis $=4.71, P=0.19$ ). There were no clutch differences related to the substratum (Kruskal-Wallis $=1.8, P>0.4$ ).

\section{BROOD SIZE}

The number of fledged chicks per successful nest was one $(n=51)$, two $(n=103)$ or three $(n=$ 10) $(\bar{x}=1.8), n=164)$. In the five colonies inspected in both years of the study, only a slight interannual variation in brood size was found. However, important variations were found among colonies (considering only those with more than five inspected nests) (Kruskal-Wallis $=20.6$, $P=0.004$ ), values ranging from 1.3 to 2.0 chicks/ nest. No significant variations due to nesting sub-

TABLE 3. Total nest loss rates estimated by the Mayfield method for the incubation and hatching periods in the colonies that were visited more than once. In the group of columns on the right the chick loss rate (brood reduction) is estimated by the same methodology. $L / E=$ number of lost nests/number of observation days; D.M.R. = Daily loss rate; $\mathrm{SE}=$ Standard error of D.M:P.

\begin{tabular}{|c|c|c|c|c|c|c|c|c|c|c|}
\hline \multirow[b]{2}{*}{ Colony } & \multirow[b]{2}{*}{ Year } & \multicolumn{3}{|c|}{ Incubation } & \multicolumn{3}{|c|}{ Nestling } & \multicolumn{3}{|c|}{ Brood reduction } \\
\hline & & $\mathrm{L} / \mathrm{E}$ & D.M.R. & $\mathrm{SE}$ & $\bar{L} / \mathrm{E}$ & D.M.R. & $\mathrm{SE}$ & $\mathrm{L} / \mathrm{E}$ & D.M.R. & $\overline{S E}$ \\
\hline \multirow[t]{3}{*}{1 (CL) } & 91 & - & - & - & $0 / 33$ & 0.0 & 0.0 & $0 / 54$ & 0.0 & 0.0 \\
\hline & 92 & - & - & - & $0 / 52$ & 0.0 & 0.0 & $1 / 94$ & 0.011 & 0.011 \\
\hline & Total & - & - & - & $0 / 85$ & 0.0 & 0.0 & $1 / 146$ & 0.007 & 0.007 \\
\hline $2(\mathrm{CL})$ & 92 & $3 / 16$ & 0.188 & 0.097 & $1 / 66$ & 0.015 & 0.015 & $1 / 38$ & 0.026 & 0.026 \\
\hline 3 (CL) & 92 & $6 / 162$ & 0.037 & 0.015 & $3 / 88$ & 0.034 & 0.019 & $0 / 52$ & 0.0 & 0.0 \\
\hline 4 (CL) & 92 & $2 / 20$ & 0.100 & 0.067 & - & - & - & - & - & - \\
\hline \multirow[t]{3}{*}{5 (TR) } & 91 & $21 / 341$ & 0.062 & 0.013 & $0 / 139$ & 0.0 & 0.0 & $1 / 161$ & 0.006 & 0.006 \\
\hline & 92 & $3 / 56$ & 0.054 & 0.030 & $0 / 176$ & 0.0 & 0.0 & $1 / 152$ & 0.007 & 0.007 \\
\hline & Total & $24 / 397$ & 0.060 & 0.012 & $0 / 315$ & 0.0 & 0.0 & $1 / 313$ & 0.009 & 0.004 \\
\hline 6 (TR) & 92 & $14 / 167$ & 0.084 & 0.021 & $5 / 162$ & 0.031 & 0.014 & $0 / 100$ & 0.0 & 0.0 \\
\hline \multirow[t]{3}{*}{8 (MS) } & 91 & $2 / 60$ & 0.033 & 0.023 & $0 / 50$ & 0.0 & 0.0 & $1 / 30$ & 0.033 & 0.033 \\
\hline & 92 & - & - & - & $1 / 122$ & 0.008 & 0.008 & $2 / 177$ & 0.011 & 0.008 \\
\hline & Total & $2 / 60$ & 0.033 & 0.023 & $1 / 172$ & 0.006 & 0.006 & $3 / 207$ & 0.014 & 0.008 \\
\hline 9 (MS) & 92 & $2 / 34$ & 0.059 & 0.024 & $4 / 68$ & 0.059 & 0.029 & $1 / 78$ & 0.013 & 0.013 \\
\hline TOTAL & & $53 / 856$ & 0.062 & 0.008 & $14 / 966$ & 0.014 & 0.004 & $7 / 934$ & 0.007 & 0.003 \\
\hline
\end{tabular}




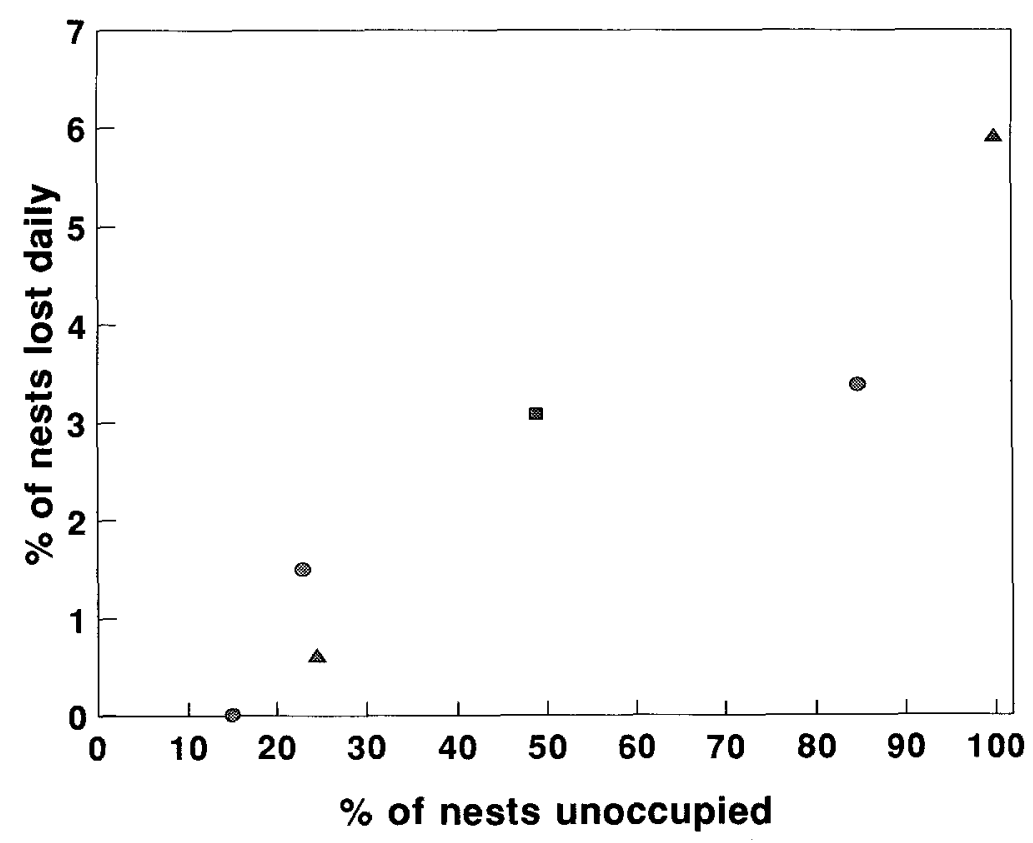

FIGURE 2. Relationship between the proportion of empty nests found during the visits performed at the time of the maximum number of nests with fledglings and the daily rate of loss of nests in each colony. One colony (number 8), that during the study period was decreasing, has been excluded. Symbols as in Figure 1.

stratum (Kruskal-Wallis $=2.7, P>0.25$ ) were found, although those colonies settled on rocks tended to have the largest brood size (1.8-2.0) and those in malline, the least (1.4-1.6) (Table 1).

\section{PHYSICAL CONDITION OF THE CHICKS}

In a given colony over the two-year period, there were no significant variations in chick quality (Mann-Witney $U$-tests). In regard to variations in chick quality among colonies, no differences were detected in single chick broods (KruskalWallis $=6.19, P>0.25$ ), but there were great differences in broods of two chicks (KruskalWallis $=30.85, P=0.001$ ). However, when variations due to substratum were taken into account (Table 2), there were no differences in chick quality in either single chick broods (Kruskal-Wallis $=2.19, P>0.1$ ) or broods of two chicks (Kruskal-Wallis $=2.57, P>0.25$ ).

\section{TOTAL LOSSES OF NESTS}

In those colonies $(1,5$, and 8$)$ where information for the two years was available, the daily nest mortality rate during incubation and growth period was not different between the two years $(P$
$>0.05$ ), so both years were treated conjointly (Table 3). Daily values ranging from $3.3 \%$ and $18.8 \%$ for incubation and $0.0 \%$ and $5.9 \%$ for growth period were observed. Nevertheless since in no case were there significant differences among them $(P>0.05)$, it can be inferred that the nesting substratum does not determine differences in the total losses of nests. Pooling data of all colonies, the daily mortality rate was $6.2 \%$ during incubation and $1.4 \%$ during growth. By considering 28 incubation days and 32 days for growth up to fledgling, only $10.6 \%$ of the nesting starts produced fledging young. The daily loss rate in every colony was highly correlated $(r=0.94, P$ $=0.005$ ) (Fig. 2) to the proportion of empty nests found at the time when the number of fledglings was the greatest (two months after the average egg-laying date). It suggests that few nest structures remain unoccupied during the breeding cycle and that most of the empty nests are due to earlier nest failure.

The causes of nest losses were mostly unknown. In colony 2, the stealing of two eggs by Chimangos (Milvago chimango) was observed. In two of the three nesting colonies (5 and 6), 11 nests were destroyed by carnivore mammals: in 
two of them an incubating adult had been killed, in another the two adults had been killed, and in eight the nestlings had been killed. Apparently the predators causing these losses were felids, possibly wild cats (Felis geoffroyi). In two malline colonies (9 and 10) we detected a total of six nests with nestlings destroyed by carnivores, probably Culpeo Foxes (Dusicyon culpaeus) or, possibly, Little Grisons (Grison cuja).

\section{PARTIAL BROOD LOSSES}

Some nests suffered the partial loss of a brood (brood reduction). By applying the Mayfield method for estimating the daily rate of brood reduction, daily values ranging from $0.0 \%$ and $3.3 \%$ (Table 3 ) were obtained. We detected no significant differences in these values among colonies. Pooling data of all the colonies, the daily mortality rate of young during rearing was $0.7 \%$.

The causes of loss were mostly unindentified. At a cliff colony (2) two chicks were found dead due to unknown causes. At two tree colonies (8 and 10), we found a nestling killed by Great Horned Owl (Bubo virginianus), one dead by plastic ingestion and another by unknown causes. At malline colonies 8 and 9, four chick corpses were found submerged in the water surrounding the nests and another dead from unknown causes.

Besides these nest losses the death of fledglings after leaving the nest was verified. At colony 1, three fledglings were found run over on the road at the cliff base. At the cliff base of colony 2, remains of six fledglings were found, five predated by carnivores and another drowned in a pond. At colony 8 we observed a Black-chested Buzzard Eagle (Geranoaetus melanoleucos) attacking unsuccessfully a fledgling sitting on the ground.

\section{DISCUSSION}

As in other colonial birds (Burger 1984, Nisbet and Welton 1984), ibis are very susceptible to human disturbance in breeding colonies (see reviews in Rodgers and Burger 1981, Hancock et al. 1992). In spite of precautions taken, the observers that performed this earlier study could have caused some disturbances (Major 1990) and, consequently, could have induced biases in the results (Parsons and Burger 1982). In our case, of the ten colonies studied, three (numbers 2, 3 and 4) were observed only with telescopes from a distance. The breeding parameters found in these colonies did not show values higher than those of the remaining colonies as would have been expected if the presence of observers had caused a higher rate of nesting failures.

Contrary to what we expected from the idealfree distribution, there was no variation in breeding success (clutch size and brood size) related to nesting substratum; there was some variation in brood size among colonies, but it was independent of the substratum. All substratum types present the same risk of total or partial brood loss. All the colonies had low breeding success, mainly associated with the very high rate of total nest loss. In all, only $11 \%$ of the nests produced fledglings.

We also hypothesized that the mean laying date in every colony would be inversely related to the potential breeding success that the birds could obtain with it. Since the breeding success was similar in all colonies, no such relationship was found. Nor did we find relationship between the laying date and the nesting substratum once altitude effect had been taken into account.

Offspring quality was similar among colonies in single chick broods. In broods of two chicks some differences, perhaps attributable to sibling competition (Brouwer and Wieringen 1990), clearly appeared. Some differences among colonies in chick quality might have been expected given that nest-site selection could be advantageous for a greater breeding success.

The low breeding success in our study is not unusual. Many studies indicated an extremely high intraspecific variability (see reviews in Hancock et al. 1992) due to numerous factors. Adverse weather and low food availability affect breeding success (Vespremeanu 1968, Miller and Burger 1978, Manry 1985, Bildstein et al. 1990, Frederick 1990). In our case, the effect of weather is not clear because loss rate was similar at the different altitudes (more losses could be expected at higher altitudes), although laying date variability could be a tempering factor. The brood reduction rate was also independent of the nesting substratum.

Predation by mammals or birds can cause important nest losses and may cause the total destruction of a colony (Parsons 1977, Manry 1978, Olmos 1990). The presence of predators can cause panic among incubating and brooding adults with desertion lasting for hours (Nisbet 1975, Nisbet and Welton 1984), and such parental neglect subjects eggs and chicks to adverse weather condi- 
tions (Burness and Morris 1993). The predator community is relatively well preserved in the study area, many avian and mammalian species reaching high densities (Novaro 1991, authors unpublished). Our data suggest that predation is usual in any kind of ibis colony. Besides the cases cited above, we know of a rock colony of about 25 pairs that was almost wholly destroyed by Little Grison predation. While inspecting nests of Grey Eagle Buzzard and Crested Caracara $\left(\mathrm{PO}_{\mathrm{O}}\right.$ lyborus plancus) that were breeding near Buffnecked Ibis, we often found remains of chicks in the raptors' nests (Donázar et al., unpubl. data).

Our results suggest that, in the population studied, nesting in different substrata is not due to a saturation that would lead to the occupation of suboptimal sites by low quality individuals. Alternatively, that the fraction of empty nests in every colony was highly related to daily loss rate suggests that the fraction of unoccupied nests must be low (but see Burger and Gochfeld 1993, for methodology). It is also possible that in an area with a limited number of breeding sites only high quality individuals would be breeding in them, in which case the birds might not show a preference for a particular substratum since all substrata present the same risks of nest loss. In fact, it has been suggested that in the absence of significant environmental variations, individuals may settle randomly in various substrata (see Orians and Wittenberg 1991). This does not mean that competition would never occur within colonies for the best nesting places (Burger 1978, 1979).

The variability found was slight and locality related, suggesting that it can be influenced by brood reduction processes that would take place under local conditions of food availability (Miller and Burger 1978, Lowe 1983, Manry 1985). Since food availability would probably vary from one year to another (Manry 1985), the directional selection necessary to fix nest-site substratum preferences could not be maintained.

\section{ACKNOWLEDGMENTS}

We are very grateful to Obdulio Monsalvo, Miguel Pineda, Javier Bustamante and Miguel Delibes for their help with the field work. Our thanks to the administrators of the Estancias Cerro de los Pinos, Chimeuin, Collun-Có, Collón-Curá, Lolén, Pilolil, and Quemquemtreu, who permitted us to work in their estates. Logistic support was provided by the Centro de Ecología Aplicada del Neuquén (Argentina); we thank Alejandro del Valle and Antonio Guiñazú for their continuous help. Financial support was provided by the lnstituto de Cooperación Iberoamericana and the Ministerio de Asuntos Exteriores (Spain) through the Programa de Cooperación Científica con Iberoamérica. The manuscript benefited from the comments of Javier Bustamante and Eduardo Aguilera. I. de Bustamante did the English translation; William Safranek also helped.

\section{LITERATURE CITED}

Alatalo, R. V., A. Lundberg, and S. Ulfstrand. 1985. Habitat selection in the Pied Flycatcher Ficedula hypoleuca, p. 59-83. In M. L. Cody [ed.], Habitat selection in birds. Academic Press, Orlando, FL.

Alonso, J. A., R. Muñoz-Pulido, AND L. M. BauTISTA. 1991. Nest-site selection and nesting success in the Azure-winged Magpie in Central Spain. Bird Study 38:45-51.

Ames, P. L., AND G. S. Merserau. 1964. Some factors in the decline of the Osprey in Connecticut. Auk 81:173-185.

Bechard, M. J., B. W. Zoellick, ANd M. Nickerson. 1985. Accuracy in determining the age of nestling Red-tailed Hawks. J. Wildl. Manage. 49:226-228.

Bildstein, K., W. Post, P. Frederick, AND J. JOHNSTON. 1990. The importance of freshwater wetlands in the breeding ecology of coastal White Ibises (Eudocimus albus): a lesson for Scarlet Ibis conservation, p. 57-63. In P. C. Frederick, L. Gonzalo Morales, A. L. Spaans, and C. S. Luthin [eds.], The Scarlet Ibis (Eudocimus ruber): status, conservation and recent research. IWRB Special Publication No. 11, Slimbridge, U.K.

Brouwer, K., AND M. V. WIERINGEN. 1990. Nesting ecology of the Scarlet Ibises (Eudocimus ruber) in a small colony of mixed ciconiiform birds in the Venezuelan llanos, p. 16-27. In P. C. Frederick, L. Gonzalo Morales, A. L. Spaans, and C. S. Luthin [eds.], The Scarlet Ibis (Eudocimus ruber): status, conservation and recent research. IWRB Special Publication No. 11, Slimbridge, U.K.

Brown, J. L. 1969. Territorial behavior and population regulation in birds. Wilson Bull. 81:293329.

Burger, J. 1978. Competition between cattle egrets and native North American herons, egrets, and ibises. Condor 80:15-23.

BURGER, J. 1979. Resource partitioning: nest site selection in mixed species colonies of herons, egrets and ibises. Am. Midl. Nat. 101:191-210.

Burger, J. 1984. Colony stability in Least Terns. Condor 86:61-67.

Burger, J., AND M. Gochfeld. 1987. Nest-site selection by the Herald Petrel and White-tailed Tropicbird on Round Island. Wilson Bull. 103: 126-130.

Burger, J., AND M. Gochfeld. 1993. When is a heronry crowded: a case study of Huckleberry Island, New York. J. Coastal Res. 9:221-228.

Burness, G. P., AND R. D. Morris. 1993. Direct and indirect consequences of mink presence in a Common Tern colony. Condor 95:708-711.

CabrerA, A. L. 1976. Regiones fitogeográficas argentinas. Enciclopedia Argentina de Agricultura y 
Jardinería. Tomo II, Fascículo 1. Aditorial ACME S.A.C.I., Buenos Aires.

Collias, N. E., AND E. C. Collias. 1984. Nest building and bird behavior. Princeton Univ. Press, Princeton, NJ.

Dhondt, A. A., B. Kempenaers, and F. Adriaensen. 1992. Density-dependent clutch size caused by habitat heterogeneity. J. Anim. Ecol. 61:643-648.

Donázar, J. A., and O. Ceballos. 1989. Growth rates of nestling Egyptian Vultures Neophron percnopterus in relation to brood size, hatching order and environmental factors. Ardea 77:217-226.

DunHaM, M. L. 1990. Nest-site selection by Boattailed Grackles. Wilson Bull. 102:702-706.

FerRer, M. 1992. El águila imperial. Quercus, Madrid.

FREDERICK, P. C. 1990. Hydrological cues associated with the initiation and abandonment of nesting by White Ibises (Eudocimus albus) in the Everglades of Florida, U.S.A., p. 64-70. In P. C. Frederick, L. Gonzalo Morales, A. L. Spaans, C. S. Luthin [eds.], The Scarlet Ibis (Eudocimus ruber): status, conservation and recent research. IWRB Special Publication No. 11, Slimbridge, U.K.

Frederick, P. C., M. G. SPalding, aNd G.V.N. Powell. 1993. Evaluating methods to measure nestling survival in Tricolored Herons. J. Wildl. Manage. $57: 34-41$.

Hancock, J. A., J. A. Kushlan, and M. P. Kahl. 1992. Storks, ibises and spoonbills of the world. Academic Press, London.

Johnson, D. H. 1979. Estimating nest success: the Mayfield method and an alternative. Auk 96:651661.

KELLY, J. P. 1993. The effect of nest predation on habitat selection by dusky flycatchers in limber pine-juniper woodland. Condor 95:83-93.

LACK, D. 1954. The natural regulation of animal numbers. Oxford Univ. Press, New York.

Li, P., AND T. E. MArtin. 1991. Nest-site selection and nesting success of cavity-nesting birds in high elevation forest drainages. Auk 108:405-418.

LowE, K. W. 1983. Egg size, clutch size and breeding success of the Glossy Ibis Plegadis falcinellus. Emu 83:31-34.

MAJOR, R. E. 1990. The effect of human observers on the intensity of nest predation. Ibis 132:608612.

MANRY, D. E. 1978. Life with Schaapen Island's Sacred Ibises-personal account. Safring News 7:1315.

MANRY, D. E. 1985. Reproductive performance of the Bald Ibis Geronticus calvus in relation to rainfall and grass-burning. Ibis 127:159-173.

Martin, T. E. 1988. Processes organizing open-nesting bird assemblages: competition or nest predation? Evol. Ecol. 2:37-50.

MARTIN, T. E., AND J. J. ROPER. 1988. Nest predation and nest-site selection of a western population of the Hermit Thrush. Condor 90:51-57.

Matheu, P., AND J. Del Hoyo. 1992. Family Threskiornithidae, p. 472-506. In J. del Hoyo, A. Elliot, and J. Sargatal [eds.], Handbook of the birds of the world. Vol. I. Ostrich to ducks. Lynx Ediciones, Barcelona.
Miller, L. M., AND J. Burger. 1978. Factors affecting nesting sucess of the Glossy Ibis. Auk 95: 353-361.

NAROSKY, T., AND D. YzuRIETA. 1988. Guia para la identificación de las aves de Argentina y Uruguay. Vázquez Mazzini Editores, Buenos Aires.

Newton, I. 1991. Habitat variation and population regulation in Sparrowhawks. Ibis 133:76-88.

NiLsson, S. G. 1984. The evolution of nest-site selection among hole-nesting birds: the importance of nest predation and competition. Omis Scand. 15:167-175.

NiLsson, S. G. 1987. Limitation and regulation of population density in the nuthatch Sitta europaea breeding in natural cavities. J. Anim. Ecol. 56: 921-937.

Nisbet, I.C.T. 1975. Selective effects of predation in a tern colony. Condor 77:221-226.

Nisbet, I.C.T., AND M. J. Welton. 1984. Seasonal variation in breeding success of Common Terns: consequences of predation. Condor 86:53-60.

Novaro, J. A. 1991. Feeding ecology and abundance of a harvested population of culpeo fox (Dusicyon culpaeus) in Patagonia. M.Sc. thesis. Univ. of Florida, Gainesville, FL.

Olmos, F. 1990. Nest predation of Plumbeous Ibis by Capuchin Monkeys and Greater Black Hawk. Wilson Bull. 102:169-170.

Orians, G. H., AND J. F. WitTENBERG. 1991. Spatial and temporal scales in habitat selection. Am. Nat. 137:29-49.

PARSONS, J. 1977. The effect of predation by Fish Eagles on the breeding success of various Ciconiiformes nesting near Kisumu, Kenya. J. Nat. Hist. 11:337-353.

Parsons, K. C., AND J. Burger. 1982. Human disturbance and nestling behavior in Black-crowned Night-Herons. Condor 84:184-187.

RICE, W. R. 1989. Analyzing tables of statistical tests. Evolution 43:223-225.

RiCKLEFs, R. E. 1969. An analysis of nesting mortality in birds. Smithson Contrib. Zool. 9:1-48.

Rodgers, J. A., JR., AND J. Burger. 1981. Concluding remarks: symposium on human disturbance and colonial waterbirds. Colonial Waterbirds 4:6970 .

Simmons, R., AND P. C. Smith. 1985. Do Northern Harriers (Circus cyaneus) choose nest sites adaptively? Can. J. Zool. 63:494-498.

Sparling, D. W., J. A. Barzen, J. R. Lovvorn, AND J. R. SERIE. 1992. An evaluation of regression methods to estimate nutritional condition of canvasbacks and other water birds. U.S. Department of the Interior. Fish and Wildlife Service. Biological Report 3. Washington, DC.

SPRINGER, M. A., AND D. R. Osborne. 1983. Analysis of growth of the Red-tailed Hawk. Ohio J. Sci. 83: 13-19.

Vespremeanu, E. E. 1968. Distribution and biology of the Spoonbill in Roumania. Ardea 56:160-177.

Watson, J. 1992. Nesting ecology of the Seychelles Kestrel Falco araea on Mahé, Seychelles. Ibis 134: 259-267. 